\title{
Physicochemical Process, Crustacean, and Microcystis Biomass Changes In Situ Enclosure after Introduction of Silver Carp at Meiliang Bay, Lake Taihu
}

\author{
Chengjie Yin, ${ }^{1,2}$ Longgen Guo, ${ }^{1}$ Chunlong Yi, ${ }^{1,2}$ Congqiang Luo, ${ }^{3}$ and Leyi $\mathrm{Ni}^{1}$ \\ ${ }^{1}$ Donghu Experimental Station of Lake Ecosystems, State Key Laboratory for Freshwater Ecology and Biotechnology of China, \\ Institute of Hydrobiology, Chinese Academy of Sciences, Wuhan 430072, China \\ ${ }^{2}$ University of Chinese Academy of Sciences, Beijing 100049, China \\ ${ }^{3}$ Collaborative Innovation Center for Efficient and Health Production of Fisheries in Hunan Province, Key Laboratory of \\ Health Aquaculture and Product Processing in Dongting Lake Area of Hunan Province, Hunan University of Arts and Science, \\ Changde 415000, China
}

Correspondence should be addressed to Longgen Guo; longgen@ihb.ac.cn

Received 2 September 2016; Accepted 23 November 2016; Published 5 January 2017

Academic Editor: Qiang Wang

Copyright (c) 2017 Chengjie Yin et al. This is an open access article distributed under the Creative Commons Attribution License, which permits unrestricted use, distribution, and reproduction in any medium, provided the original work is properly cited.

In order to control cyanobacteria blooms with silver carp in Lake Taihu, an in situ experiment was carried out by stocking silver carp at a biomass of 35,70 , and $150 \mathrm{~g} \mathrm{~m}^{-3}$ and no carp control in waterproof enclosures. Physicochemical water parameters and biomass of plankton were measured in enclosures to evaluate the suitable stocking density of silver carp for relieving internal nutrients and constraining cyanobacteria growth in Lake Taihu. It is found that the $35 \mathrm{~g} \mathrm{~m}^{-3}$ silver carp group and $70 \mathrm{~g} \mathrm{~m}^{-3}$ silver carp group presented lower total phosphorus, lower chlorophyll- $a$, and higher water transparency. Increased nitrogen to phosphorus ratio, which indicated the result of algae decline in fish presence enclosures, was attributed to decline of phosphorus. Phosphorus decline also exerted limitation on reestablish of cyanobacteria bloom. Crustacean zooplankton biomass and Microcystis biomass decreased significantly in fish presence enclosures. Silver carp could be more effective to regulate algae bloom in enclosures with dense cyanobacteria. Therefore, nonclassic manipulation is supposed to be appropriate method to get rid of cyanobacteria blooms in Lake Taihu by stocking 35 to $70 \mathrm{~g} \mathrm{~m}^{-3}$ silver carp in application.

\section{Introduction}

In freshwater ecosystems, fish affect the structure and dynamics of pelagic plankton communities by trophic cascading effects $[1,2]$, which usually relates consumers to their environments by food web chains [3]. Removal of planktivorous fish could relieve the predation pressure on zooplankton community by top-down control; thus the enhancement of crustaceans zooplankton leads to decline of algal density $[4,5]$. This method, used to be defined as classic biomanipulation, however, usually malfunctions [6] because the presence of zooplankton grazing-resistant species such as frequent carpet of fetid cyanobacteria disables or weakens top-down force in nutrient enrichment lakes. Moreover, as the absence of large size zooplankton such as Daphnia in these lakes, crustacean communities are not able to control algal bloom by zooplankton-target manipulation: indeed grazing pressure by zooplankton is useless [7].

Introduction of filter-feeding planktivorous fish to hypertrophic shallow freshwater lakes successfully is another effective method to regulate the algal community which is called nonclassic biomanipulation [8-10]. As for nonclassic biomanipulation, planktivorous fish directly collect food by filtering water via their gill rakers and hence, unselectively ingest plankton and detritus. However, the ecological effects of filter-feeding fish introduced to specific lakes have remained 

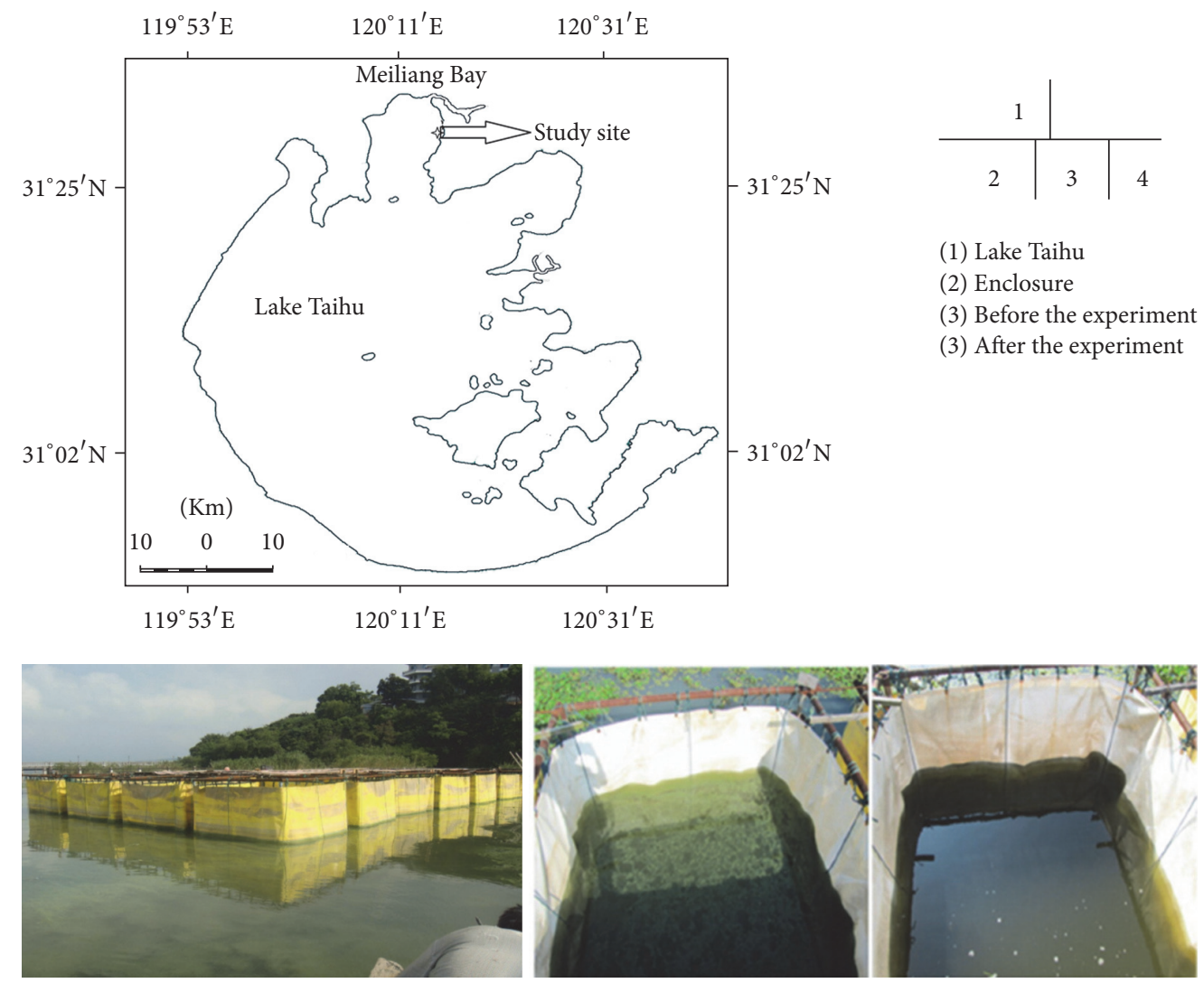

FIgURE 1: The study site and experimental enclosures.

controversial [5]. Three conditions for successful control of algae by planktivorous fish's grazing should be taken into account: (1) the stocking density and body size of filterfeeding silver carp [5]; (2) the initial plankton species pool [11] and (3) environmental conditions [12].

Lake Taihu is the third largest shallow freshwater lake located at the lower reach of the Yangtze River. Due to accumulative nutrient-rich sewage and agricultural run-off inflow, it became eutrophic with heavy cyanobacteria blooms from late spring to autumn every year in last decades [13]. In this lake, dominant crustacean zooplankton has changed from large body sized individuals, such as Daphnia, to small ones, such as Limnoithona sinensis during the last 60 years [14]. Hence, biomanipulation method to control algal blooms to improve water quality became impossible in Lake Taihu. As for nonclassic biomanipulation successfully in the hypereutrophic Lake Donghu, we consider using filterfeeding planktivorous fish to control cyanobacteria blooms in situ enclosure experiments in Lake Taihu.

Some previous studies $[9,10]$ investigated the ecological and biological effects of planktivorous silver carp and bighead carp with a certain density in large pen/enclosure at Meiliang Bay and Gonghu Bay, which are all located at the most serious bloom area in Lake Taihu. But we could not obtain optional stocking density of planktivorous fishes to control the dense algal blooms in this lake. Therefore, we carried out in situ enclosure experiments to explore the suitable stocking density of filter-feeding silver carp on controlling cyanobacteria blooms and hope to enhance fisheries resources for sustainable development based on decreasing the algal blooms and reasonable fish biodiversity in future.

\section{Materials and Methods}

2.1. Experiment Site and Device Settlement. Our experiment was located at Meiliang Bay $\left(31^{\circ} 31-325^{\prime} \mathrm{N}, 120^{\circ} 09-340^{\prime} \mathrm{E}\right.$, Figure 1), which is administrated by Wuxi City, Jiangsu Province (Figure 1). Meiliang Bay receives heavy nutrient loads and has suffered eutrophication with serious algal blooms. The mean total phosphorus (TP) and total nitrogen (TN) are $0.1 \mathrm{mg} \mathrm{L}^{-1}\left(\max 0.2 \mathrm{mg} \mathrm{L}^{-1}\right)$ and $2.3 \mathrm{mg} \mathrm{L}^{-1}(\max$ $\left.5.6 \mathrm{mg} \mathrm{L}^{-1}\right)$ in the northern east of Meiliang Bay [9, 15].

Four facets cuboid waterproof PVC enclosures $(2.5 \times 2.5$ $\times 3 \mathrm{~m}$ installed in water depth at approximate $1.5 \mathrm{~m}$ littoral zone) were fixed to a cage of steel pipes. Bottom margins of each enclosure with heavy stone cages were sank into the lake sediment as possible to avoid water exchange between inside and outside of the enclosure during the study period. Its cost is about 3000 YUAN (equal to about 450 USD) per enclosure including all the materials and labour costs.

2.2. Study Protocol and Sampling Collection. Planktivorous fish silver carp (average weight $137 \mathrm{~g} \pm 3 \mathrm{~g}$ ) were obtained 
from a local aquatic farm and then acclimated in a nearby pond until they were transferred into the enclosures. The whole experiment aimed to explore the proper density of silver carp to control algae bloom.

In this experiment, 12 enclosures were chosen and randomly divided into four groups with triplications representing for control group (CG), low fish density group (LDG), medium fish density group (MDG), and high density group (HDG). CG, LDG, MDG, and HDG had fish biomass at 0 , 35,70 , and $150 \mathrm{~g} \mathrm{~m}^{-3}$. The experiment lasted from 30th May to 23rd June 2011 with a sampling interval of 3-4 days depending on the local weather. The average cyanobacteria biomass before the experiment in each enclosure was approximate about $5.8 \mathrm{~g} \mathrm{~L}^{-1}$ before the fish were introduced (confirmed with 2010 Microcystis biomass).

2.3. Experimental Parameters. Integrated water sample was collected by a 5 liter modified Patalas's bottle sampler. We determined water temperature, dissolved oxygen (DO), total dissolved solids (TDS), and $\mathrm{pH}$ using YSI Professional Plus (YSI Inc., Yellow Springs, Ohio, USA) water quality monitor. Water transparency was determined by using a $20-\mathrm{cm}$ in diameter Secchi's disk and represented as Secchi's depth $\left(Z_{\mathrm{Sd}}\right)$. Turbidity was measured by a turbidimeter (Model TN100, Eutech Instrument, Pte Ltd., Singapore).

$50 \mathrm{~mL}$ samples of quantitative crustaceans were collected by filtering $10 \mathrm{~L}$ integrated water samples through $25^{\#}(69 \mu \mathrm{m})$ plankton net and then fixed with $1 \mathrm{~mL}$ saturated formalin. All individuals were counted after precipitation for 1 day by using an Olympus compound microscope (model BH2-RFC; Olympus America, Inc., Melville, NY, USA) at total $4 \times$ 10 magnification in the samples to calculate density and biomass. Copepods and cladocerans were identified based on these papers $[16,17]$, and their wet weight was calculated according to the formula of these papers $[18,19]$. Integrated water samples fixed with $1 \mathrm{~mL}$ saturated formaldehyde solution that was set volume to $50 \mathrm{~mL}$ was prepared for Microcystis spp. quantitative measurement. Colonial Microcystis was broken up to individual cells by an ultrasonic wave cell knapper (Model JY88-II, SCIENIZ, Ningbo, Zhejiang Prov., China) so that single cells could be counted. Fixed samples $(0.1 \mathrm{~mL})$ were tested using Olympus compound microscope under magnification of $40 \times 10$. Wet weight of Microcystis was calculated based on the formula of this paper [19]. All samples were collected at 7:00-8:30 a.m. to minimize variations between each sampling point.

Water chemistry including ammonia nitrogen $\left(\mathrm{NH}_{4}{ }^{+}\right)$, nitrate nitrogen $\left(\mathrm{NO}_{3}{ }^{-}\right)$, total nitrogen $(\mathrm{TN})$, dissolved inorganic phosphorus, total dissolved nitrogen (TDN), total dissolved phosphorus (TDP), total phosphorus (TP), and chlorophyll-a were determined based on [20]. Microcystis was measured at a sampling interval between two sampling points, and water chemistry was tested on every sampling point.

In this experiment, physicochemical water parameters, zooplankton, and Microcystis spp. data were collected. Regressions analysis among physiochemical parameters over the fish groups was undertaken to investigate interactions of each parameter.

2.4. Statistical Analysis. Data were normalized and variance was adjusted for homogeneity before analysis. Means of dissolved oxygen, $\mathrm{pH}$, total dissolved solids, and transparency were compared between control group and each treatment during whole experiment using independent $T$-test. Chemical parameters and chlorophyll-a indicators with treatments and time as two factors were subjected to two-way ANOVA (analyze of variance) using post hoc multiple by comparisons test (LSD) [21] and expressed as means \pm standard deviation (STDEV). Data for regression analyses were subjected to $\ln (x+1)$ transformation. Differences were measured against control values and considered to be statistically significant at $P<0.05$. Statistical analyses mentioned above were undertaken using SPSS (Statistical Product and Service Solutions, IBM Inc.) 13.0 for Windows. Statistical figures were output by $\mathrm{R}[22]$ and OriginPro 8.0 (OriginLab Corporation).

\section{Results}

3.1. Physicochemical Water Parameters. In this experiment, water temperature varied from $22.1^{\circ} \mathrm{C}$ to $26.2^{\circ} \mathrm{C}$ (lowest and highest values were recorded on 30th May and 3rd July). $\mathrm{pH}$ and total dissolved solids did not show significant different between control group and each treatment. MDG showed the lowest dissolved oxygen in the whole experiment. Higher fish density group presented lower dissolved oxygen. In the LDG, transparency was measured to be significantly higher than in the CG whereas the lowest occurred in the HDG and even lower than in the CG (Table 1).

3.2. Nutrients Change. Nitrate and ammonia were found to be significantly higher $\left(P<0.05, \mathrm{df}_{7,3}\right.$, other statistics were shown in Figure 2) in MDG and HDG during this experiment. Dissolved inorganic phosphorus was lowest in MDG (Figure 3). Total dissolved nitrogen was lowest in LDG, increased with increasing fish biomass and highest in no fish group (Figure 3). None of differences were found between treatments in total dissolved phosphorus and total nitrogen (Figure 4). Chlorophyll-a and total phosphorus were lower in $\mathrm{LDG}$ and MDG that compared with control and HDG (Figure 5).

During this experiment, $\mathrm{TN}$ : TP ratio values were lowest in CG (Table 2). Significant difference of TN : TP value was found between CG and MDG $(P=0.028, t=-2.27)$. Regression analyzes in fish groups between chlorophyll-a to $\mathrm{TN}$ and $\mathrm{TP}$ showed that $\mathrm{TP}$ was positively related to chlorophyll-a $(P<0.001, r=0.413)$ while TN was less relative $(P=0.095, r=0.2)$ to chlorophyll-a fluctuate (Table 3$)$. Regression analyzes showed that TN was positively related to TN : TP $(P<0.001, r=0.856)$ while TP was not related to $\mathrm{TN}: \mathrm{TP}(P=0.514, r=-0.079)$.

Transparency $\left(Z_{\mathrm{Sd}}\right)$ was negative related to Microcystis $(P<0.01, r=-0.47)$, TP $(P<0.01, r=-0.33)$, and chlorophyll-a $(P=0.01, r=-0.54)$. But TN was not observed related to all these parameters (Table 3 ). 


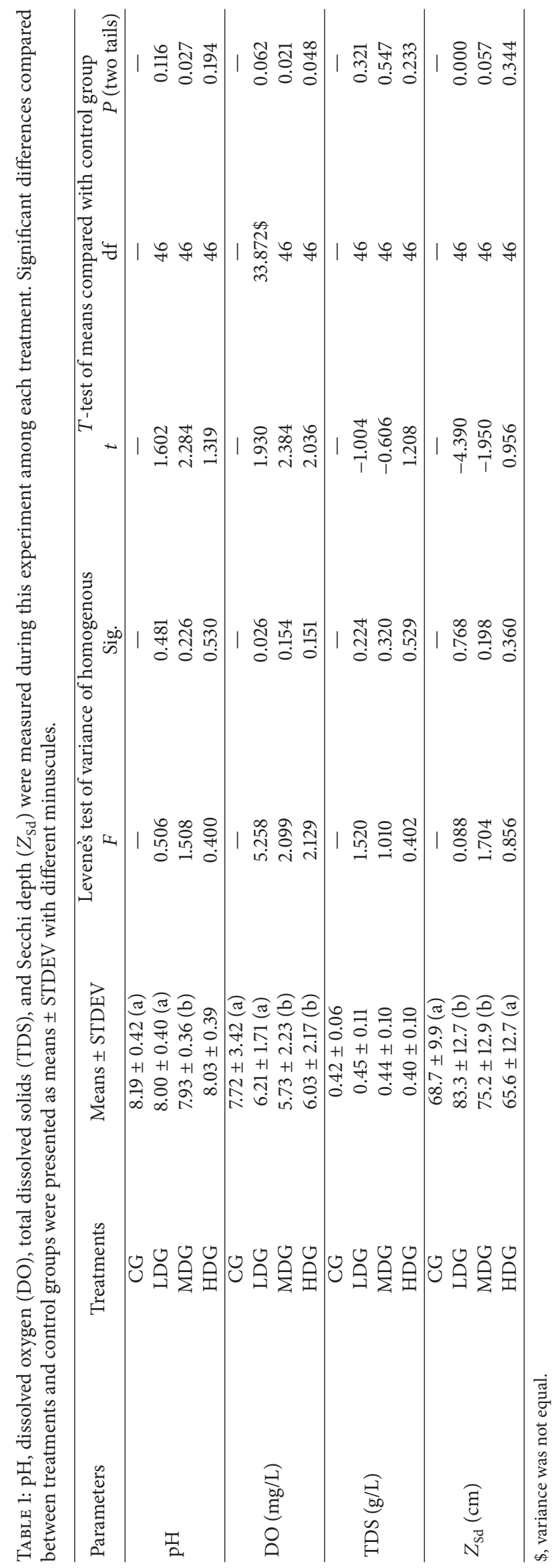



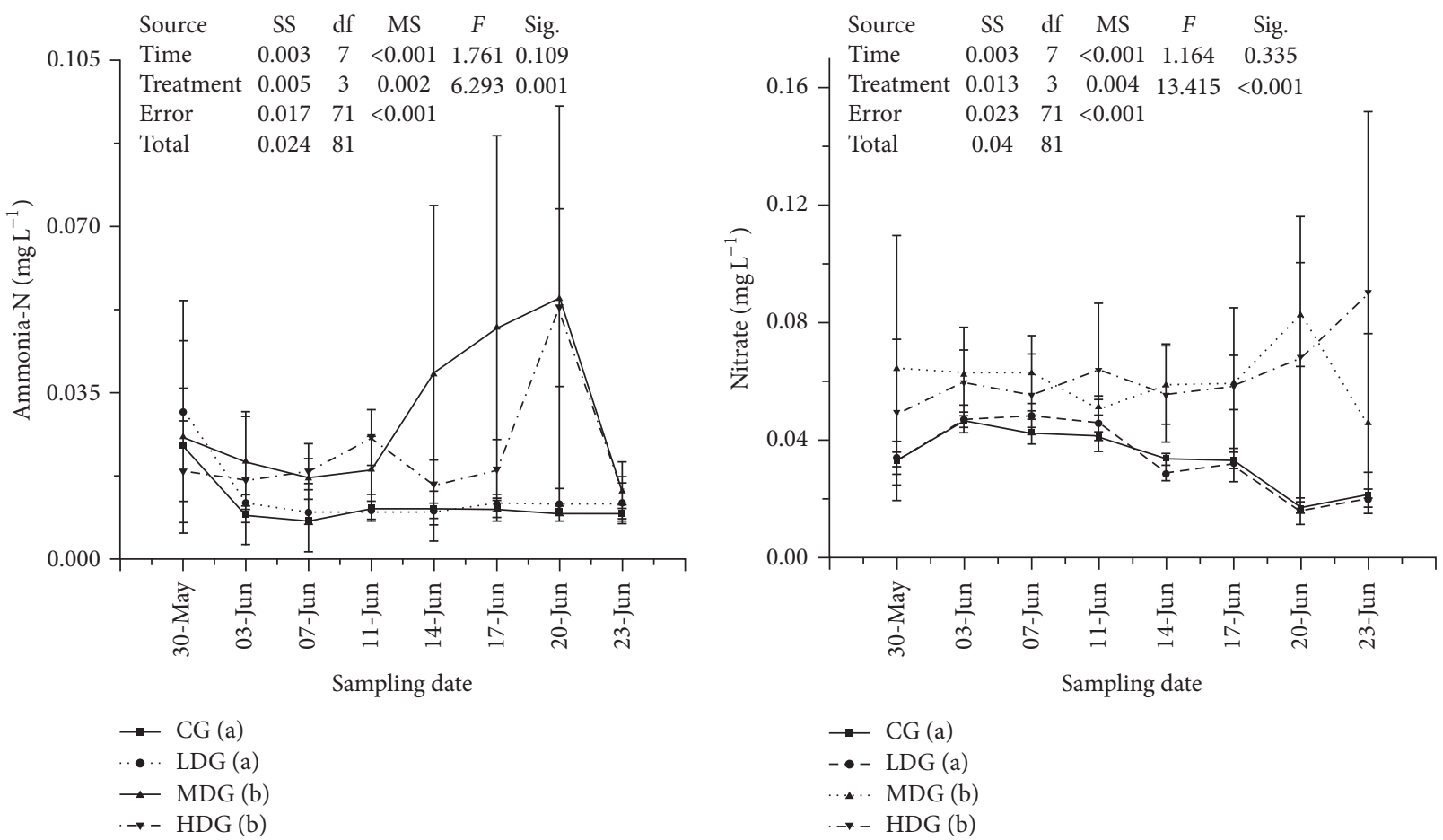

FIGURE 2: Nutrients values including ammonia and nitrate in each enclosure treatment during sampling points. Values were presented by mean \pm STDEV. Treatments with different minuscules mean significant differences between each other and parameters in each treatment from low to high were arranged alphabetically (i.e., treatment with minuscule (a) means the lowest, at $P<0.05, \alpha=0.05$ ). SS: type III sum of squares, df: freedom, and MS: mean square.
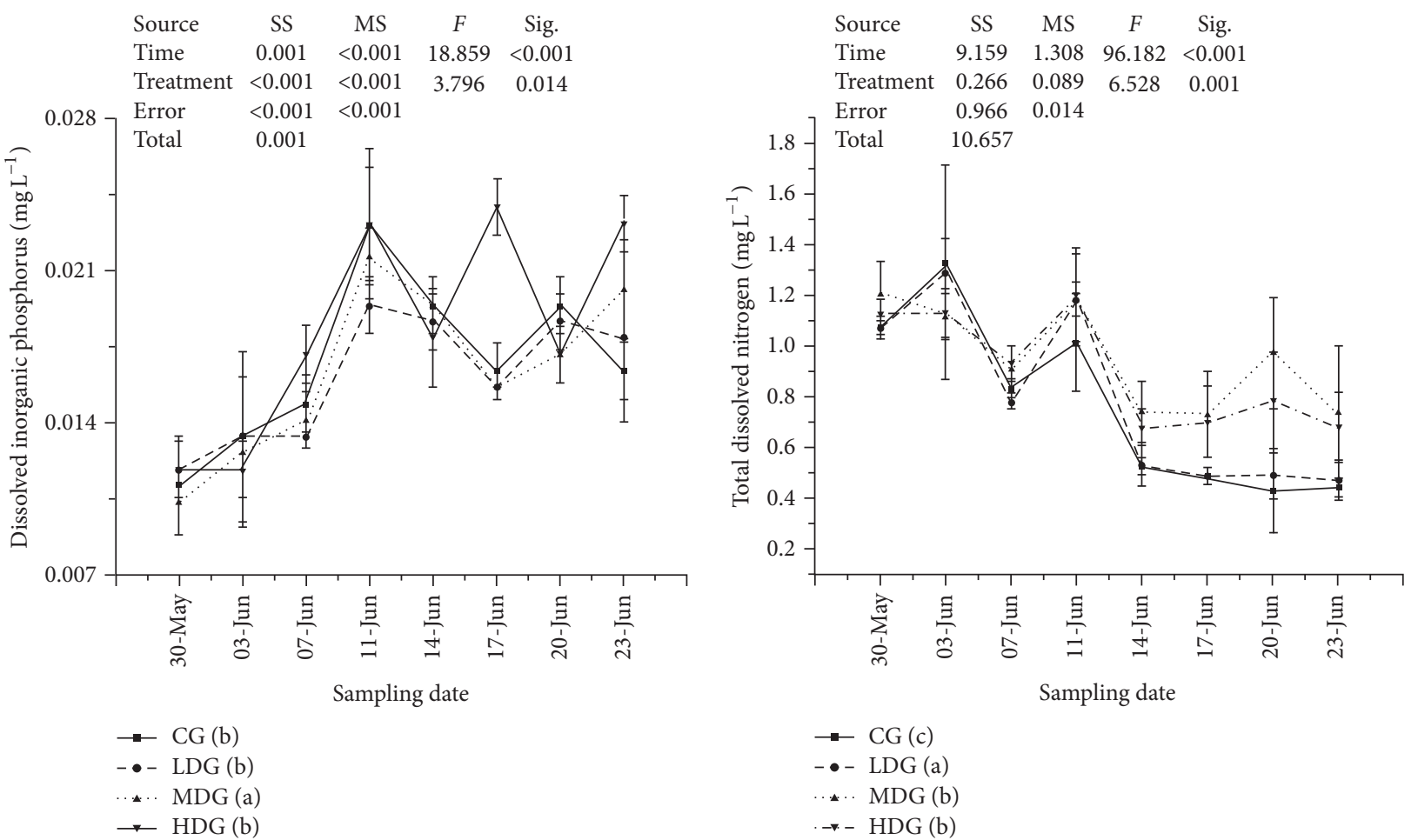

FIGURE 3: Nutrients values including dissolved inorganic phosphorus and total dissolved nitrogen in each enclosure treatment during sampling points. Values were presented by mean \pm STDEV. Treatments with different minuscules mean significant differences between each other and parameters in each treatment from low to high were arranged alphabetically (i.e., treatment with minuscule (a) means the lowest, at $P<0.05, \alpha=0.05)$. SS: type III sum of squares, df: freedom, and MS: mean square. 

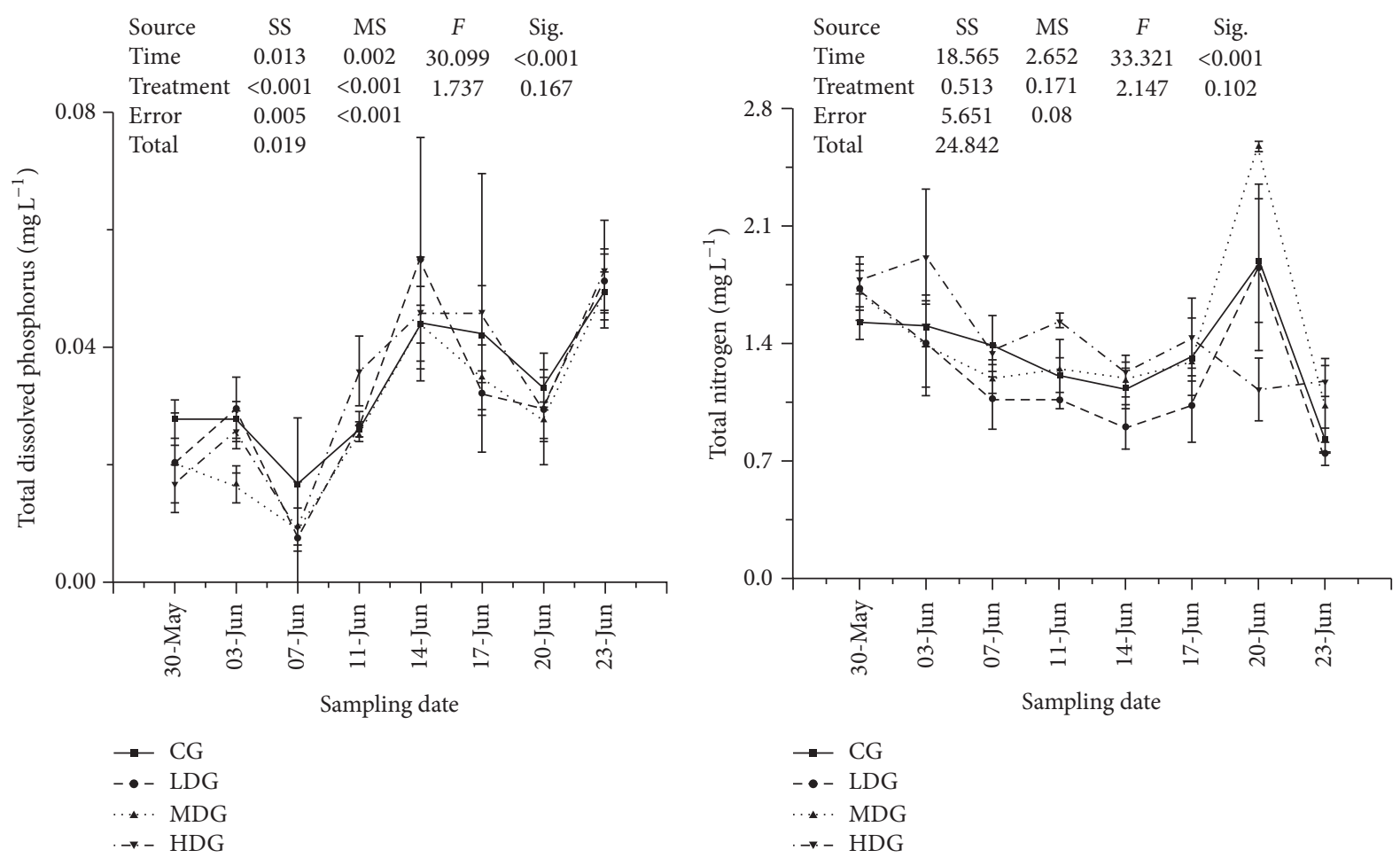

FIGURE 4: Nutrients values including total dissolved phosphorus and total nitrogen in each enclosure treatment during sampling points. Values were presented by mean \pm STDEV. No significant differences between each other and parameters in each treatment. SS: type III sum of squares, df: freedom, and MS: mean square.
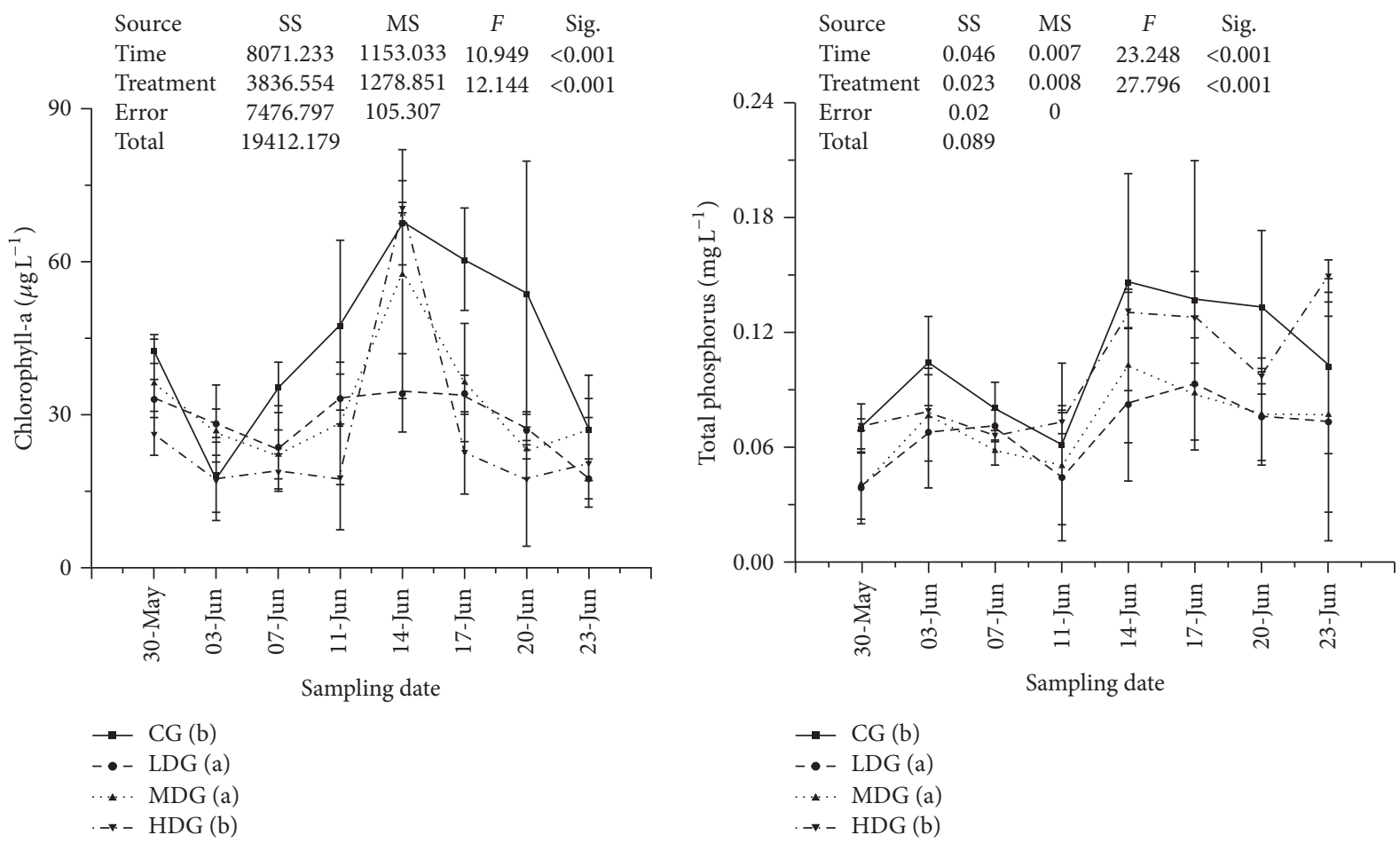

Figure 5: Nutrients values including total phosphorus and chlorophyll-a in each enclosure treatment during sampling points. Values were presented by mean \pm STDEV. Treatments with different minuscules mean significant differences between each other and parameters in each treatment from low to high were arranged alphabetically (i.e., treatment with minuscule (a) means the lowest, at $P<0.05, \alpha=0.05$ ). SS: type III sum of squares, df:freedom, and MS: mean square. 
TABLE 2: N : P ratio values and comparison between CG and treatments for each treatment. Results of TN : TP ratio are performed as mean \pm STDEV; means with asterisk “*” stand for significant difference (T-test).

\begin{tabular}{|c|c|c|c|c|c|c|}
\hline \multirow[t]{2}{*}{ Group } & \multirow{2}{*}{$\begin{array}{l}\mathrm{TN} \text { : } \mathrm{TP} \text { ratio } \\
\text { values }\end{array}$} & \multicolumn{2}{|c|}{$\begin{array}{l}\text { Test for equality of } \\
\text { variances }\end{array}$} & \multicolumn{3}{|c|}{$T$-test for equality of means } \\
\hline & & $F$ & Sig. & $t$ & $\mathrm{df}$ & Sig. \\
\hline$\overline{C G}$ & $12.43 \pm 6.57$ & & & d with $\mathrm{CC}$ & & \\
\hline LDG & $14.70 \pm 7.58$ & 0.670 & 0.418 & -1.095 & 45 & 0.279 \\
\hline MDG & $17.72 \pm 9.31^{*}$ & 2.230 & 0.134 & -2.271 & 46 & 0.028 \\
\hline HDG & $13.87 \pm 7.71$ & 1.908 & 1.908 & -0.693 & 46 & 0.492 \\
\hline
\end{tabular}

TABLE 3: Pearson (upper-right corner) and Spearman's rank (lower-left corner) correlation coefficients $(r)$ between variables. TP: total phosphorus, $\mathrm{TN}$ : total nitrogen, $\mathrm{NO}_{3}$ : nitrate, $\mathrm{NH}_{4}$ : ammonia, $\mathrm{MC}$ : Microcystis, $Z_{\mathrm{Sd}}$ : Secchi depth, and Chla: chlorophyll-a.

\begin{tabular}{|c|c|c|c|c|c|c|c|c|}
\hline & $\mathrm{TP}$ & TN & $\mathrm{NO}_{3}$ & $\mathrm{NH}_{4}$ & $\mathrm{MC}$ & $\mathrm{pH}$ & $Z_{\mathrm{Sd}}$ & Chla \\
\hline $\mathrm{TP}$ & & 0.57 & 0.13 & 0.10 & 0.21 & 0.03 & 0.00 & 0.01 \\
\hline $\mathrm{TN}$ & -0.07 & & 0.86 & 0.84 & 0.18 & 0.14 & 0.16 & 0.10 \\
\hline $\mathrm{NO}_{3}$ & -0.49 & 0.21 & & 0.01 & 0.17 & 0.45 & 0.63 & 0.05 \\
\hline $\mathrm{NH}_{4}$ & 0.03 & -0.03 & 0.37 & & 0.89 & 0.34 & 0.88 & 0.07 \\
\hline $\mathrm{MC}$ & 0.54 & -0.16 & -0.10 & 0.40 & & 0.01 & 0.00 & 0.32 \\
\hline $\mathrm{pH}$ & 0.04 & -0.29 & 0.31 & 0.30 & 0.36 & & 0.76 & 0.44 \\
\hline$Z_{\mathrm{Sd}}$ & -0.33 & 0.21 & -0.22 & -0.11 & -0.47 & -0.43 & & 0.01 \\
\hline Chla & 0.43 & 0.20 & 0.35 & 0.27 & 0.44 & 0.72 & -0.54 & \\
\hline
\end{tabular}

3.3. Microcystis spp. and Crustaceans. Mean Microcystis during this experiment was lowest in the LDG while the highest was in the CG. The mean Microcystis biomass was significantly different in the fish groups to the control (Table 4). Dominant crustacean zooplanktons in our study were identified as Limnoithona sinensis, Mesocyclops leuckarti, Thermocyclops taihokuensis, Bosmina spp., and Diaphanosoma spp. Other zooplankton species were also found: Ceriodaphnia cornuta, Sinocalanus dorrii, Thermocyclops spp., Canthocamptus spp., and Moina micrura. During this experiment, crustaceans decreased significantly in the fish enclosures (Table 4).

\section{Discussion}

In the present study, fish at the lower density $\left(35 \mathrm{~g} \mathrm{~m}^{-3}\right.$ to $70 \mathrm{~g} \mathrm{~m}^{-3}$ ) inhibited cyanobacteria blooms more efficiently. These enclosures performed as refined water quality, lower nutrient, and cyanobacteria density; relative higher zooplankton biomass than higher fish group.

The vital debates on successful biomanipulations in a long period usually depend on whether they can efficiently release internal load [23]. Closed system, just like in the present study, soluble nutrients, for example, $\mathrm{NH}_{4}{ }^{+}$and $\mathrm{NO}_{3}{ }^{-}$, increased with increasing fish density, indicating density dependent effects that fish interfere water chemical process by their metabolism. Studies have illustrated TN, TP, and chlorophyll-a in the fish presence enclosures significantly lower than in the fish absence [24]. At relatively low densities, the silver carp were able to graze for particles of food directly, resulting in a decline in phosphorus and chlorophylla levels within the Lake Taihu enclosures [25]. Hence, the threshold of fish density usually should be taken into account for evaluating the risk and the advantage that fish could bring out. If the systems were enlarged to full-lake scale manipulation, the results are mixed at best.

The authors reported that reduction of stocking fish density promoted water quality in four Netherlands and Denmark shallow lakes [26]. Pond study also supported the result [27]. In the 1990s, an in situ enclosure experiment of silver carp manipulation was carried out in Lake Donghu, the experimental results showed that stocking density of 46$50 \mathrm{~g} \mathrm{~m}^{-3}$ silver carp can more effectively control the algae bloom, and the algae bloom was removed accompanied with decreased nutrients, which is similar to our experimental results [8]. Previous study proposed that water quality in pen stocked with about $40 \mathrm{~g} \mathrm{~m}^{-3}$ filter-feeding silver carp near our experiment area did not differ from outside water because of the large water exchange both inside and outside pen area [9]. The authors countered those 3 cases out of 11 filter-feeding fish biomanipulations in enclosure experiments which showed decreased total phosphorus, while 5 cases showed no effects and remaining 3 cases showed increased total phosphorus [28]. These evidences prove that filter feedings fish could interfere with water physicochemical process, so we want to study how the filter feedings fish could interfere with water physicochemical process.

In the present study, the increasing value of total nitrogen to total phosphorus ratio in fish presence enclosures indicated that cyanobacteria bloom was alleviated by fish, by referring 
TABLE 4: Crustacean and Microcystis biomass for each treatment. Statistics are performed as mean \pm STDEV; means with different minuscules stand for significant difference.

\begin{tabular}{|c|c|c|c|c|}
\hline \multirow{2}{*}{ Variable } & \multicolumn{4}{|c|}{ Treatments } \\
\hline & CG & LDG & MDG & HDG \\
\hline \multirow{2}{*}{ Crustacean biomass $(\mu \mathrm{g} / \mathrm{L})$} & \multirow{2}{*}{$87.67 \pm 23.50$ (a) } & $12.34 \pm 6.77(b)$ & $6.89 \pm 4.34(\mathrm{~b})$ & $7.03 \pm 5.51(b)$ \\
\hline & & $P<0.01$ & $P<0.01$ & $P<0.01$ \\
\hline \multirow{2}{*}{ Microcystis spp. biomass (mg/L) } & \multirow{2}{*}{$6.53 \pm 2.44(\mathrm{a})$} & $2.55 \pm 0.43(\mathrm{c})$ & $4.18 \pm 0.37(\mathrm{~b})$ & $3.94 \pm 0.22(b)$ \\
\hline & & $P<0.01$ & $P=0.042$ & $P=0.031$ \\
\hline
\end{tabular}

cyanobacteria bloom explosion usually results in decline of $\mathrm{TN}$ : TP ratio [29]. In the present study, $\mathrm{N}$ did not decrease by fish's grazing, and consequently, increased TN : TP ratio in fish groups should be caused by TP decline. This means the top-down effects by fish to algal community was triggered by $\mathrm{P}$ fluctuation. Usually, $\mathrm{P}$ is considered to be the first regulatory factor that can limit growth of algae communities, while $\mathrm{N}$ is the secondary factor [30]. According to the positive relation between TP and chlorophyll-a in the present study, P decline promoted the possibility of limitation of algal growth from bottom-up, even though the absolute phosphorus (average $\mathrm{TP}>150 \mu \mathrm{g} \mathrm{L}^{-1}$ ) and nitrogen (average $\mathrm{TN}>1 \mathrm{mg} \mathrm{L}^{-1}$ ) in the study area were enough for the cyanobacteria growth.

\section{Conclusions}

The present study provide evidences that, in enclosure conditions, fish at a density of $35 \mathrm{~g} \mathrm{~m}^{-3}$ to $70 \mathrm{~g} \mathrm{~m}^{-3}$ could be effective in controlling Microcystis blooms, promotion of fish production, and ameliorating the aquatic environment. Nonclassic biomanipulation is a proper means to reduce nutrients and phytoplankton under conditions of (1) eutrophic or hypereutrophic water, (2) lack of large sized zooplankton, and (3) dominance of filamentous or colonial algae.

\section{Competing Interests}

The authors declare that there is no conflict of interests regarding the publication of this paper.

\section{Acknowledgments}

This study was supported by the National Science and Technology Ministry (no. 2014BAC09B02) and the National High Technology Research and Development Program of China (Grant no. 2012ZX07105-004).

\section{References}

[1] K. Christoffersen, B. Riemann, A. Klysner, and M. Sondergaard, "Potential role of fish predation and natural populations of zooplankton in structuring a plankton community in eutrophic lake water," Limnology and Oceanography, vol. 38, no. 3, pp. 561573, 1993.

[2] M. Coll and K. Hargadon, "Trophic and functional cascades in tropical versus temperate aquatic microcosms," Aquatic Ecology, vol. 46, no. 1, pp. 55-71, 2012.
[3] M. Gophen, "Biomanipulation: retrospective and future development," Hydrobiologia, vol. 200-201, no. 1, pp. 1-11, 1990.

[4] D. J. McQueen, J. R. Post, and E. L. Mills, “Trophic relationships in freshwater pelagic ecosystems," Canadian Journal of Fisheries and Aquatic Sciences, vol. 43, no. 8, pp. 1571-1581, 1986.

[5] I. Domaizon and J. Devaux, "Experimental study of the impacts of silver carp on plankton communities of eutrophic Villerest reservoir (France)," Aquatic Ecology, vol. 33, no. 2, pp. 193-204, 1999.

[6] P. Xie and J. K. Liu, "Practical success of biomanipulation using filter-feedingfish to control cyanobacteria blooms: a synthesis of decades of research and application in a subtropical hypereutrophic lake," TheScientific WorldJournal, vol. 1, pp. 337356, 2001.

[7] H. Ma, F. Cui, Z. Fan, Z. Liu, and Z. Zhao, "Efficient control of Microcystis blooms by promoting biological filter-feeding in raw water," Ecological Engineering, vol. 47, pp. 71-75, 2012.

[8] P. Xie, Silver Carp and Bighead, and Their Use in the Control of Algal Blooms, Science Press, Beijing, China, 2003.

[9] Z. Ke, P. Xie, L. Guo, Y. Liu, and H. Yang, "In situ study on the control of toxic Microcystis blooms using phytoplanktivorous fish in the subtropical Lake Taihu of China: a large fish pen experiment," Aquaculture, vol. 265, no. 1-4, pp. 127-138, 2007.

[10] L. G. Guo, Q. Wang, P. Xie et al., "A non-classical biomanipulation experiment in Gonghu Bay of Lake Taihu: control of Microcystis blooms using silver and bighead carp," Aquaculture Research, vol. 46, no. 9, pp. 2211-2224, 2015.

[11] S. Datta and B. B. Jana, "Control of bloom in a tropical lake: grazing efficiency of some herbivorous fishes," Journal of Fish Biology, vol. 53, no. 1, pp. 12-24, 1998.

[12] M. Fukushima, N. Takamura, L. Sun, M. Nakagawa, K. Matsushige, and P. Xie, "Changes in the plankton community following introduction of filter-feeding planktivorous fish," Freshwater Biology, vol. 42, no. 4, pp. 719-735, 1999.

[13] L. Guo, "Doing battle with the green monster of Taihu Lake," Science, vol. 317, no. 5842, article 1166, 2007.

[14] X. Sun, M. Tao, B. Qin et al., "Large-scale field evidence on the enhancement of small-sized cladocerans by Microcystis blooms in Lake Taihu, China," Journal of Plankton Research, vol. 34, no. 10, pp. 853-863, 2012.

[15] M. Tao, P. Xie, J. Chen et al., "Use of a generalized additive model to investigate key abiotic factors affecting microcystin cellular quotas in heavy bloom areas of lake Taihu," PLOS ONE, vol. 7, no. 2, Article ID e32020, 2012.

[16] S. C. Chiang and N. S. Du, Fauan Sinica, Crustacea, Freshwater Cladocera, Science Press, Beijing, China, 1979.

[17] J. R. Sheng, Fauna Sinica, Crustacea, Freshwater Copepoda, Science Press, Beijing, China, 1979. 
[18] X. F. Huang and C. Y. Hu, Regression Equations of the Body Weight to Body Length for Common Freshwater Species of Cladocera, Transaction of the Chinese Crustacean Society, Science Press, Beijing, China, 1986.

[19] Z. S. Zhang and X. F. Huang, Research Methods of Freshwater Plankton, Science Press, Beijing, China, 1991.

[20] A. E. Greenberg, L. S. Clesceri, and A. D. Eaton, Standard Methods for the Examination of Water and Wastewater, American Public Health Association, Washington, DC, USA, 1992.

[21] R. G. D. Steel and J. H. Torrie, Principles and Procedures of Statistics, A Biometrical Approach, McGraw-Hill, New York, NY, USA, 2nd edition, 1980.

[22] R Core Team, $R$ : A Language and Environment for Statistical Computing, R Foundation for Statistical Computing, Vienna, Austria, 2014, http://www.R-project.org/.

[23] R. Drenner and K. D. Hambright, "Piscivores, trophic cascades, and lake management," The Scientific World Journal, vol. 2, pp. 284-307, 2002.

[24] C. L. Yi, L. G. Guo, L. Ni, and C. Luo, "Silver carp exhibited an enhanced ability of biomanipulation to control cyanobacteria bloom compared to bighead carp in hypereutrophic Lake Taihu mesocosms," Ecological Engineering, vol. 89, pp. 7-13, 2016.

[25] C. Yi, L. Guo, L. Ni, C. Yin, J. Wan, and C. Yuan, "Biomanipulation in mesocosms using silver carp in two Chinese lakes with distinct trophic states," Aquaculture, vol. 452, pp. 233-238, 2016.

[26] M. L. Meijer, E. Jeppesen, E. van Donk et al., "Long-term responses to fish-stock reduction in small shallow lakes: interpretation of five-year results of four biomanipulation cases in The Netherlands and Denmark," Hydrobiologia, vol. 275, no. 1, pp. 457-466, 1994.

[27] I. J. Holopainen, W. M. Tonn, and C. A. Paszkowski, "Effects of fish density on planktonic communities and water quality in a manipulated forest pond," Hydrobiologia, vol. 243-244, no. 1, pp. 311-321, 1992.

[28] X. Zhang, P. Xie, and X. Huang, "A review of nontraditional biomanipulation," The Scientific World Journal, vol. 8, pp. 11841196, 2008.

[29] P. Xie, A Review on the Cause of Cyanobacterial Blooms from an Evolutionary, Biogeochemical and Ecological View of Point, Science Press, Beijing, China, 2007.

[30] H.-J. Wang, X.-M. Liang, P.-H. Jiang, J. Wang, S.-K. Wu, and H.-Z. Wang, "TN: TP ratio and planktivorous fish do not affect nutrient-chlorophyll relationships in shallow lakes," Freshwater Biology, vol. 53, no. 5, pp. 935-944, 2008. 

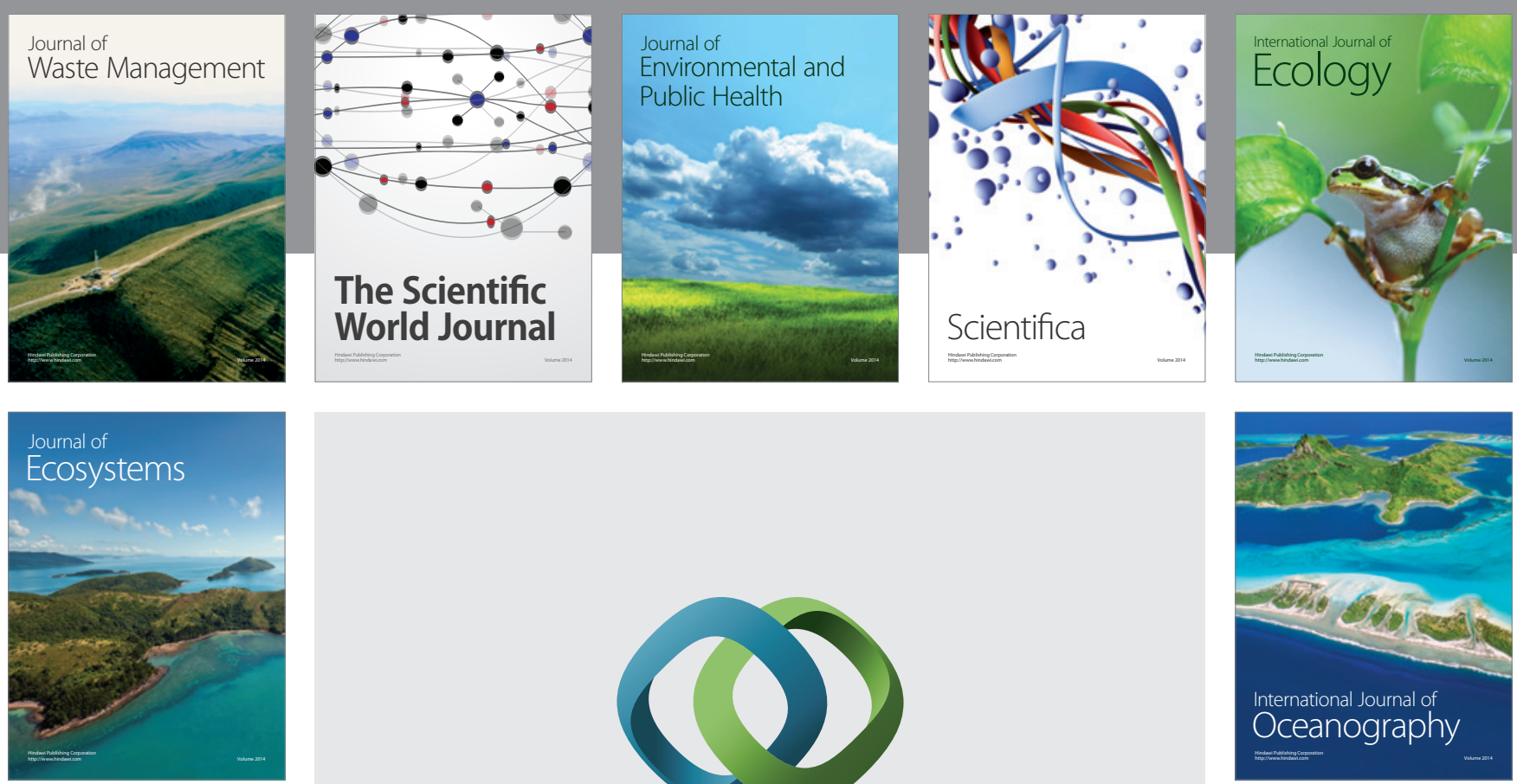

The Scientific World Journal
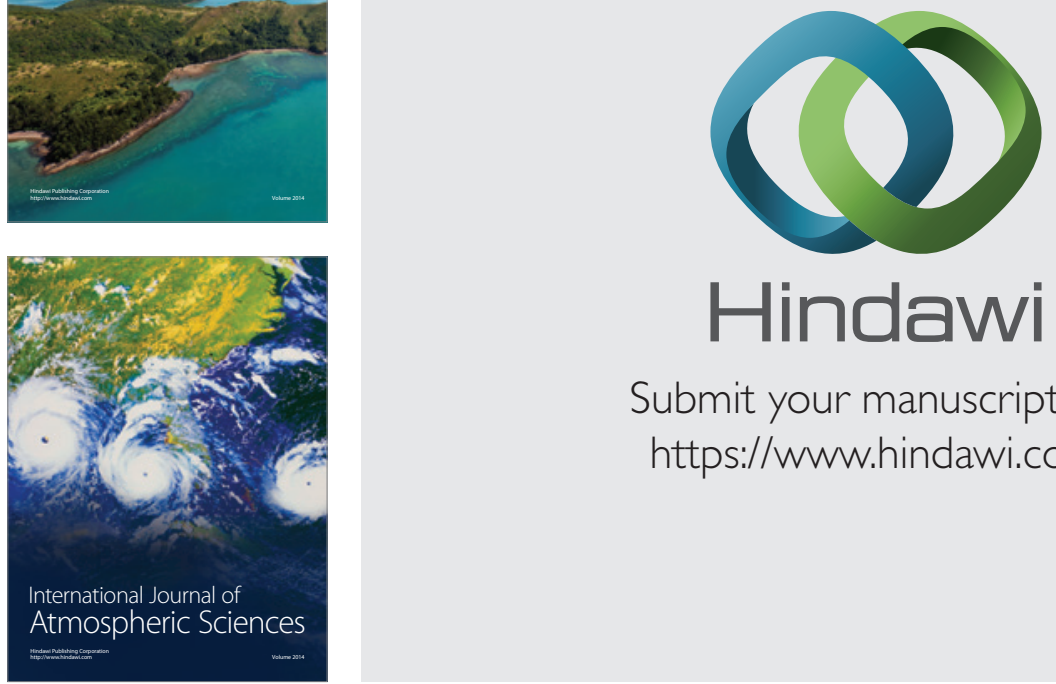

Submit your manuscripts at

https://www.hindawi.com
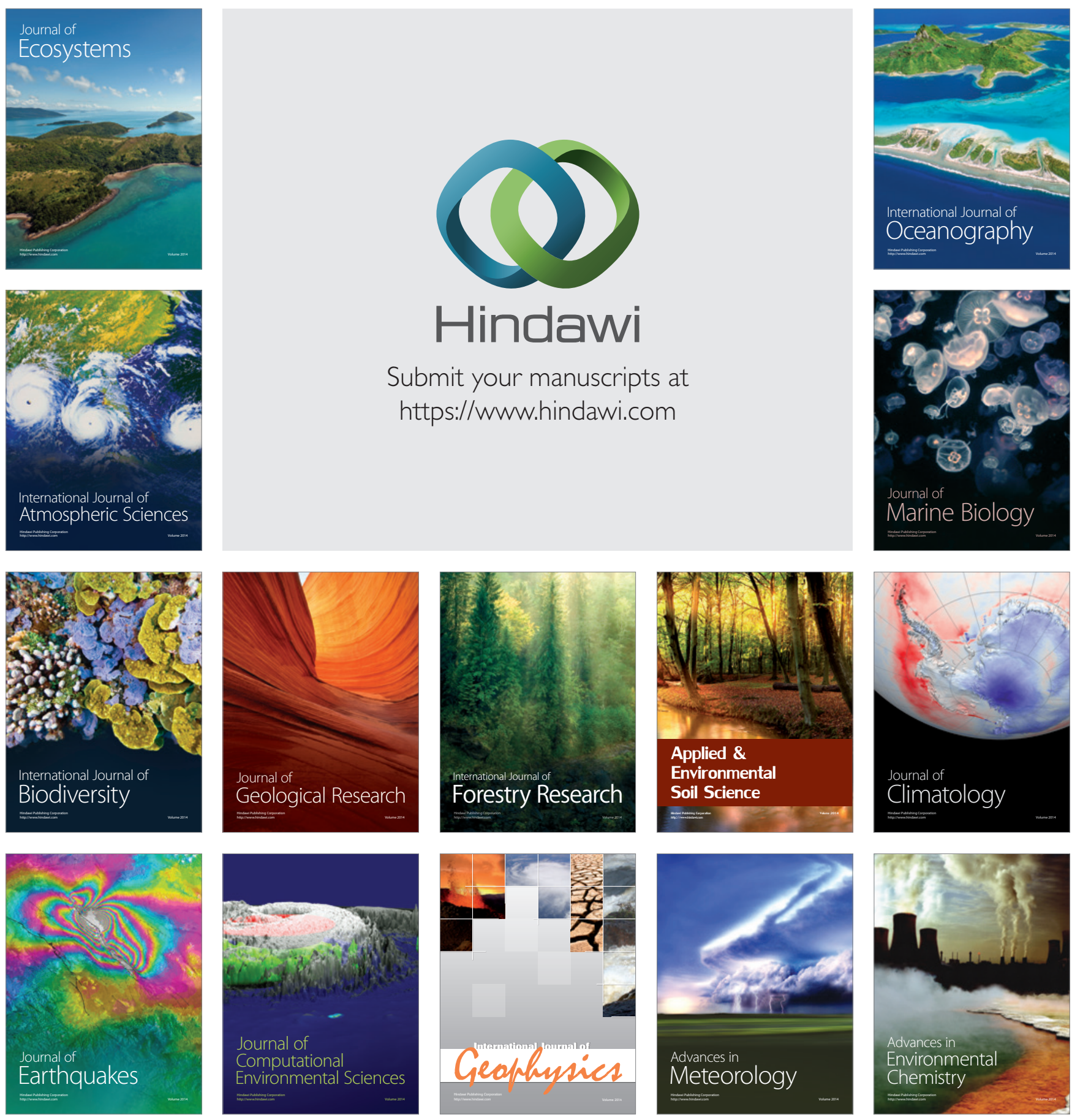